\title{
Investigating the Prevalence of Musculoskeletal Disorders in Melli Bank Staff and Determining Its Relationship with Office Tension in North Khorasan Province in 2019
}

\author{
Seyed Taghi Mirmohammadi ${ }^{1}$ (D), Osman Gook ${ }^{2 *(D)}$, Seyed Nouroddin Mousavinasab ${ }^{3}$ (D) \\ Hadi Mahmoodi Sharafe ${ }^{4}$ (D)
}

1. Department of Occupational Health Engineering, Research \& Technology, Faculty of Health, Mazandaran University of Medical Sciences, Sari, Iran

2. Department of Occupational Health Engineering, Research \& Technology, Faculty of Health, Mazandaran University of Medical Sciences, Sari, Iran

3. Department of Biostatistics, Research \& Technology, Faculty of Health, Mazandaran University of Medical Sciences, Sari, Iran

4. Department of Occupational Health Engineering, Student Research Committee, Faculty of Health, Mazandaran University of Medical Sciences, Sari, Iran

\begin{tabular}{|c|c|}
\hline Article Info & ABSTRACT \\
\hline $\begin{array}{l}\text { Received: 2019/11/04; } \\
\text { Accepted: 2020/01/10; } \\
\text { ePublished: 2020/02/29 } \\
\text { doi) 10.30699/jergon.7.4.31 } \\
\begin{array}{c}\text { Use your device to scan } \\
\text { and read the article online }\end{array}\end{array}$ & $\begin{array}{l}\text { Background and Objectives: Bank staff do much of their work using computers, } \\
\text { Their equipment and layout may put the body in an inappropriate position and lead } \\
\text { to musculoskeletal disorders (MSDs), so this study aimed to determine the } \\
\text { prevalence of MSDs in bank staff and its relationship with office tensions. } \\
\text { Methods: This descriptive cross-sectional study was performed on } 173 \\
\text { employees of Melli Bank of North Khorasan Province. The prevalence of MSDs was } \\
\text { estimated through CMDQ, Risk factors were estimated through ROSA and data were } \\
\text { entered into SPSS } 20 \text {. Then their relationship with each other and with the equipment } \\
\text { layout was determined by Spearman test. } \\
\text { Results: The mean ROSA scores were } 4.73 \pm 0.793 \text { and } 63.6 \% \text { of the postures } \\
\text { were in the intervention group. The mean CMDQ scores were } 103.63 \pm 181.004 \text {. } \\
\text { Spearman test showed a good correlation between ROSA and CMDQ results } \\
\text { (P=0.021, R=0.175). There was a significant relationship between work experience } \\
\text { and prevalence of MSDs ( } P=0.037 \text {, R=0.159). Kruskal-Wallis test showed a } \\
\text { significant relationship between education level and CMDQ scores ( } P=0.38 \text { ). The } \\
\text { most common disorders in the organs were neck ( } 53.8 \%) \text { and lower back ( } 49.7 \% \text { ). } \\
\text { Conclusion: Given the correlation between the ROSA results and the CMDQ, } \\
\text { they can be used together. The change should be considered immediately for persons } \\
\text { who are in intervention group. The chair and monitor played a more important role } \\
\text { in raising the ROSA score. Improvements should be made by providing an } \\
\text { ergonomic chair as well as a proper layout of other equipment such as a monitor. }\end{array}$ \\
\hline
\end{tabular}

Keywords: Musculoskeletal disorders, ROSA, CMDQ, Office work

Copyright $(\odot)$ 2020, This is an original open-access article distributed under the terms of the Creative Commons Attribution-noncommercial 4.0 International License which permits copy and redistribute of the material just in noncommercial usages with proper citation.

\section{How to Cite This Article:}

Mirmohammadi T, Gook O, Mousavi nasab N, Mahmoodi sharafe H. Investigating the Prevalence of Musculoskeletal Disorders in Melli Bank Staff and Determining Its Relationship with Office Tension in North Khorasan Province in 2019. Iran J Ergon. 2020; 7 (4):31-39 


\section{بررسى شيوع اختلالات اسكلتى عضلانى كاركنان بانك ملى و تعيين ارتباط آن با تنش ادارى در استان خراسان

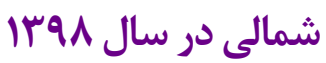

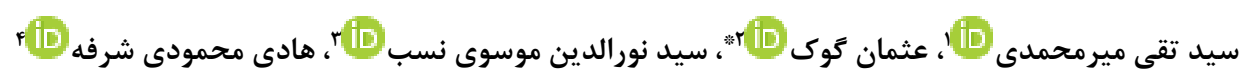

' . استاديار و هيئتعلمى، گروه بهداشت حرفهاى، دانشكدة بهداشت، دانشخاه علوميزشكى مازندران، سارى، ايران

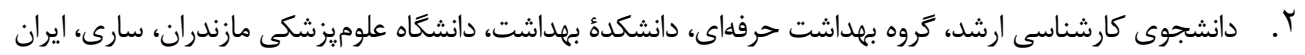

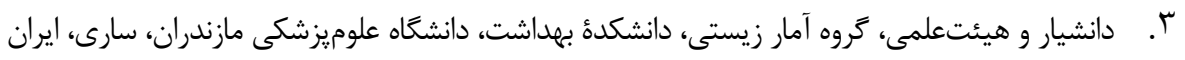

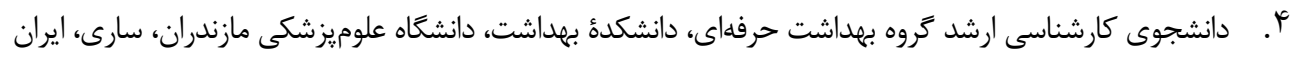

\begin{tabular}{|c|c|}
\hline 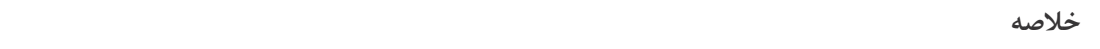 & 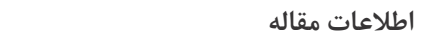 \\
\hline زمينه و هدف: كارمندان بانك بخش زيادى از كار خود را با رايانه انجام مىدهند. تجهيزات و جيدمان & 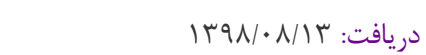 \\
\hline آنها ممكن است بدنشان را در وضعيت نامناسبى قرار دهد و به اختلالات اسكلتى-عضلانى منجر شود؛ & 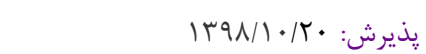 \\
\hline \multirow{2}{*}{ بنابراين مطالعه حاضر با هدف تعيين شيوع اختلالات اسكلتى-عضلانى كارمندان بانكى و ارتباط آن با تنش } & 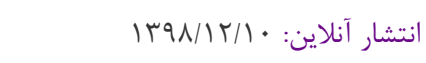 \\
\hline & \multirow{5}{*}{ 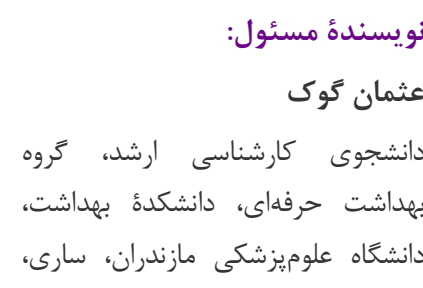 } \\
\hline روش كار: در اين مطالعه توصيفى-مقطعى، IVT كارمند بانك ملى استان خراسان شمالى بررسى شدهاند. شيوع & \\
\hline اختلالات اسكلتى-عضلانى (MSDs) به كمك يرسشنامئ اختلالات اسكلتى-عضلانى كرنل (CMDQ) و ريسك & \\
\hline & \\
\hline 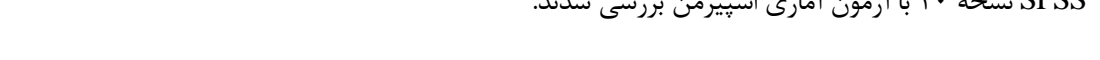 & \\
\hline \multicolumn{2}{|l|}{ 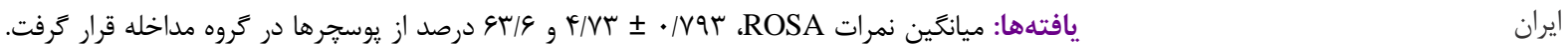 } \\
\hline \multirow{4}{*}{ 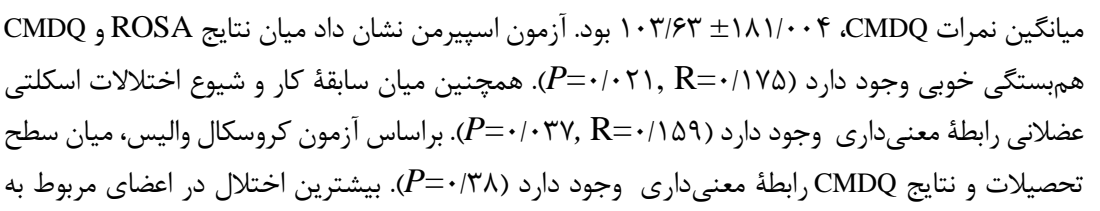 } & 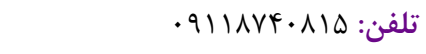 \\
\hline & 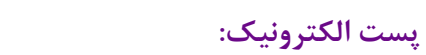 \\
\hline & gook.osman@gmail.com \\
\hline & \\
\hline ناحية كردن ( & مقاله، كد زير را. \\
\hline \multirow{4}{*}{ 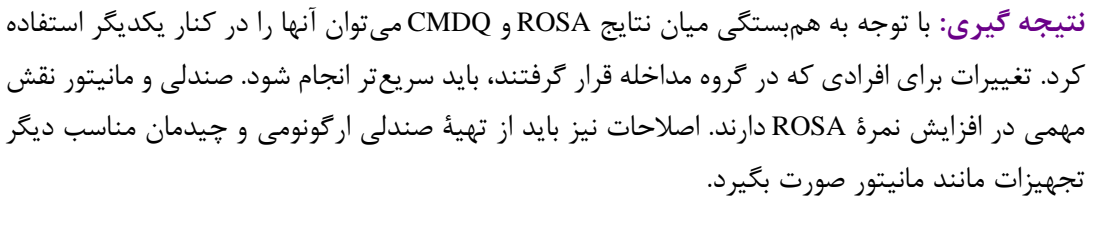 } & O \\
\hline & \\
\hline & \\
\hline & O. \\
\hline كليدوازهها: اختلالات اسكلتى -عضلانى، CMDQ ROSA، كار ادارى & \\
\hline
\end{tabular}

مقل مه

عضلانى مرتبط است. شيوع اين اختلالات در كشورهاى درحال توسعه با توجه به نوع كار و مدت تماس با ايستخاه كار

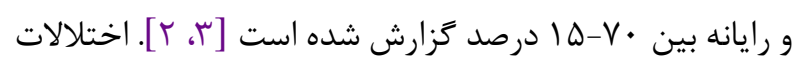
اسكلتى -عضلانى در عصب، عضله، تاندون، مفصل و... به وجود

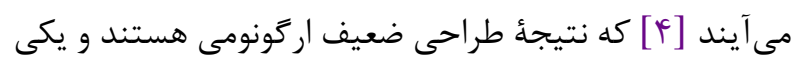

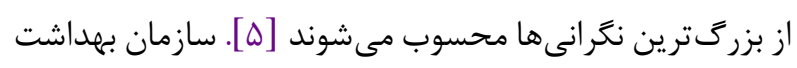

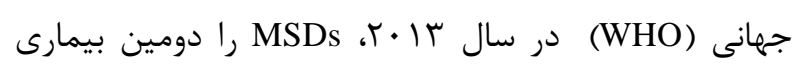

امروزه كمتر شغلى را مىتوان يافت كه در آن از رايانه

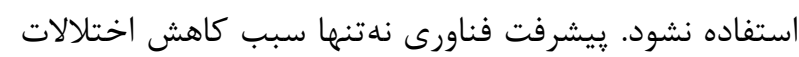

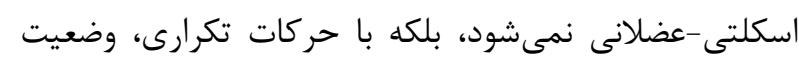

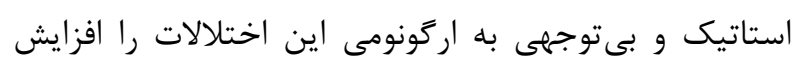

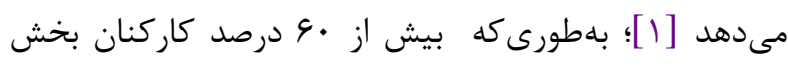

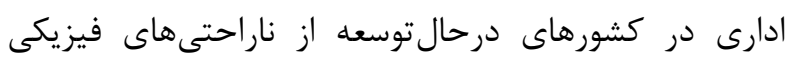
شكايت دارند كه بسيارى از اين شكايتها با اختلالات اسكلتى ـ دارئ 
نيز بررسى شد. با توجه به يوسجر كارى افراد بهكمك روش ROSA

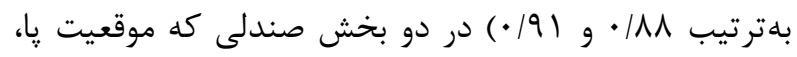

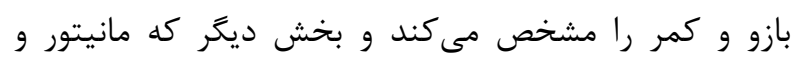

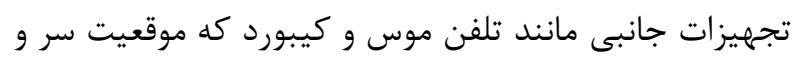

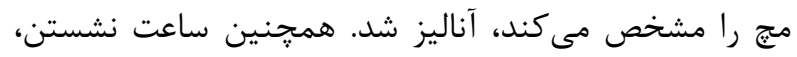

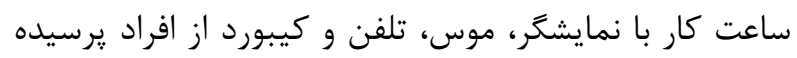

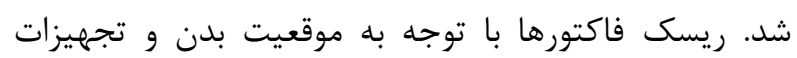

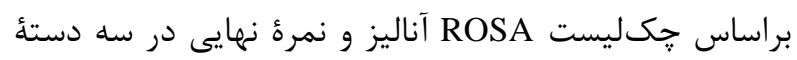

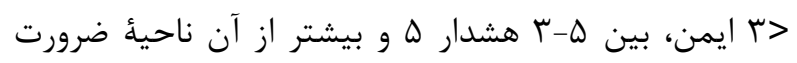

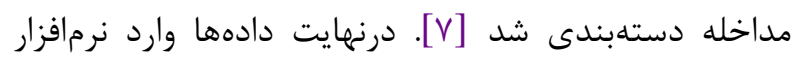
SPSSver20 طريق ROSA برآورد شود. همجنين شيوع اختلالات نيز از

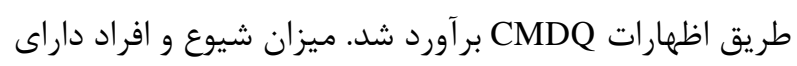

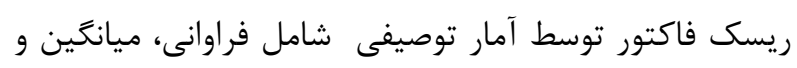

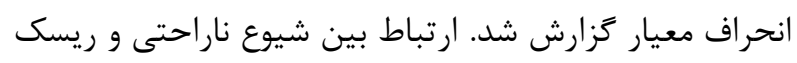

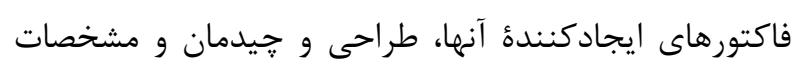

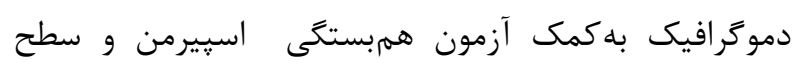

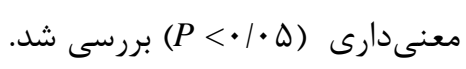

يافته ها

نتايج آناليز يوسجر به روش

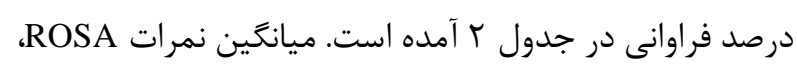

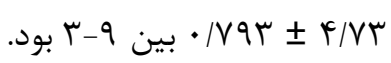

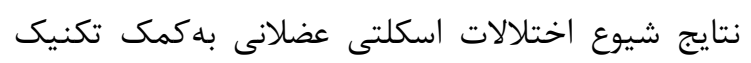

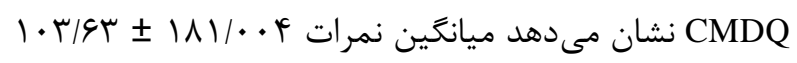

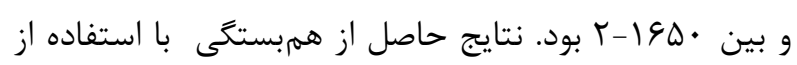

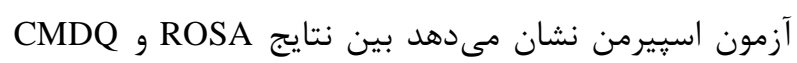

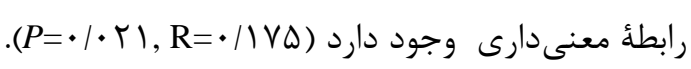
بررسى همبستخى مشخصات دموكرافيك مانند سن،

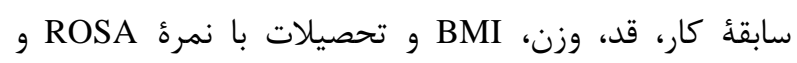

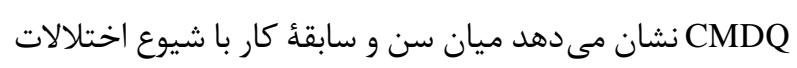

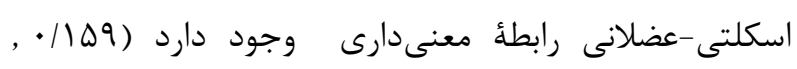

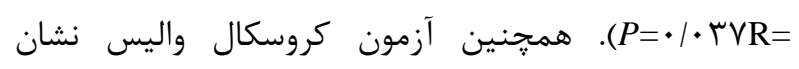

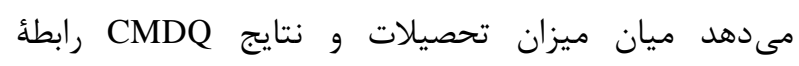

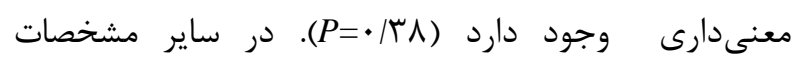
دموكرافيك اين ارتباط معنادار نبود.

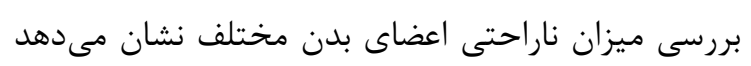

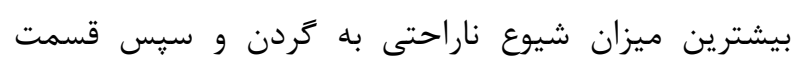

شايع مرتبط با كار رتبهبندى كرد [\&]. با توجه به مواجهات

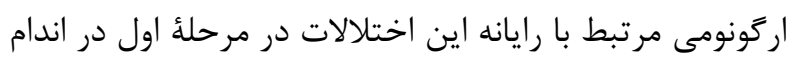

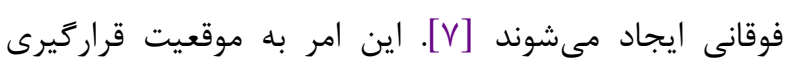

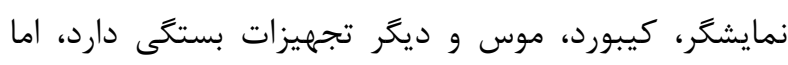

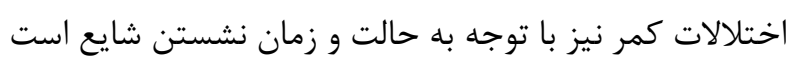

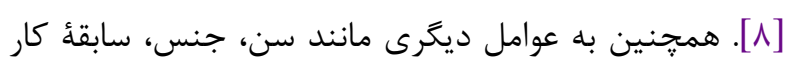

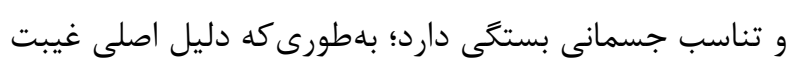

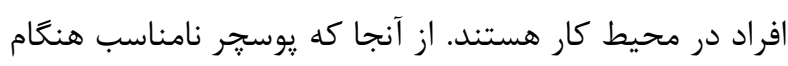

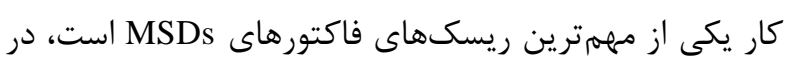

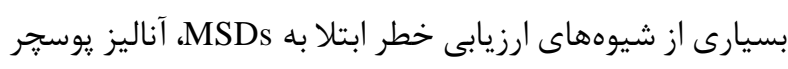

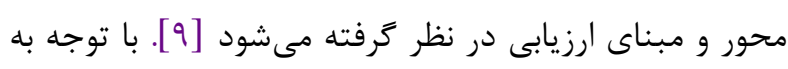

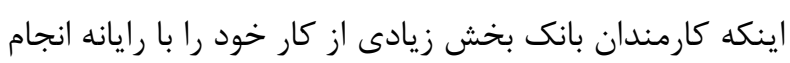

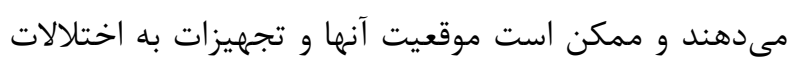

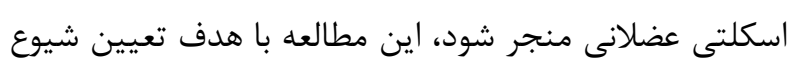
اختلالات اسكلتى-عضلانى كارمندان بانك ملى استى استان خراسان

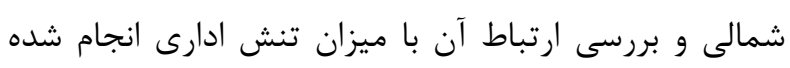

\section{روش كار}

مطالعهٔ توصيفى-مقطعى حاضر بلهورت سرشمارى بر

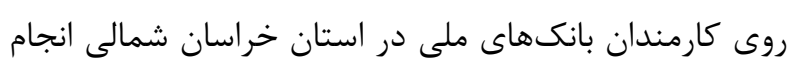

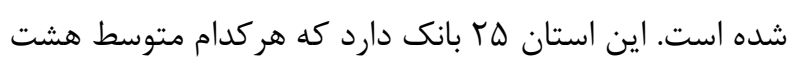

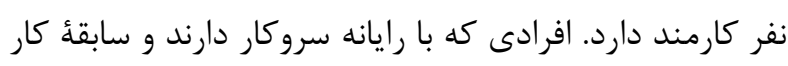

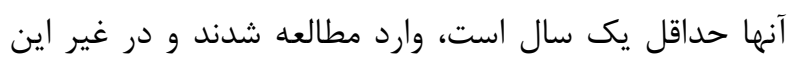

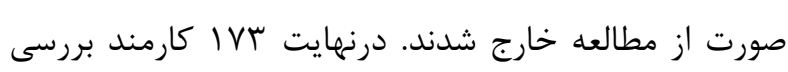

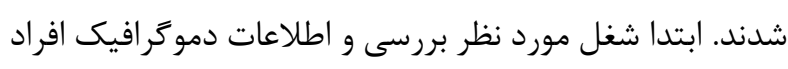

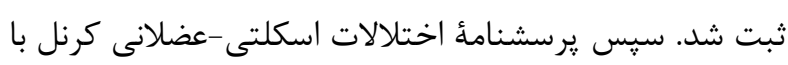

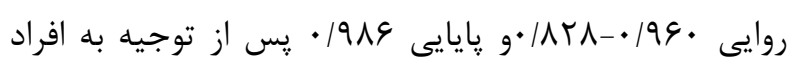

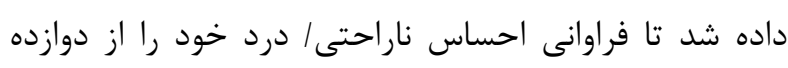

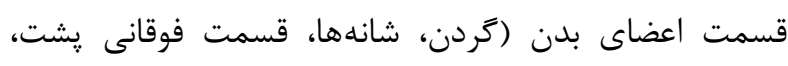

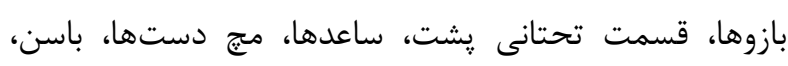

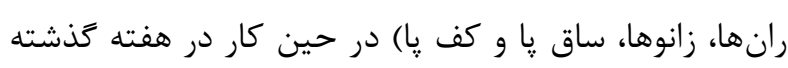

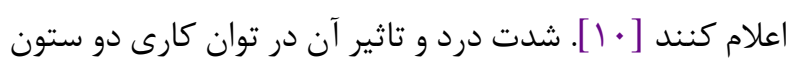

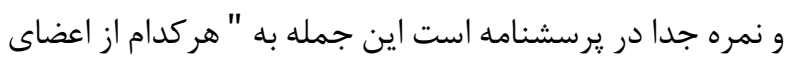

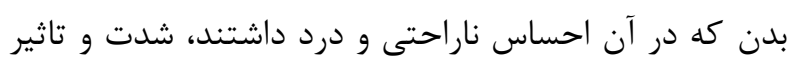

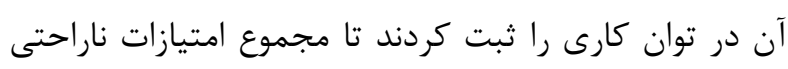

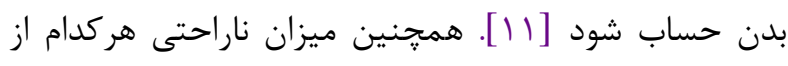

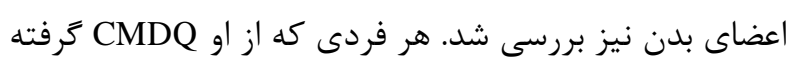

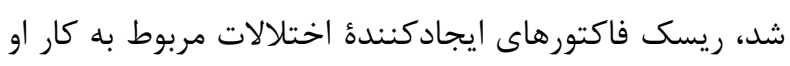




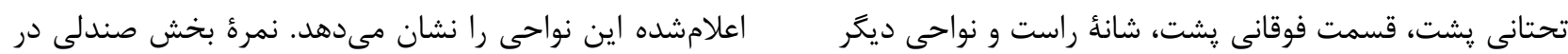

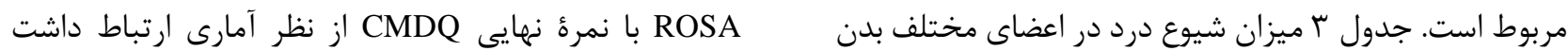

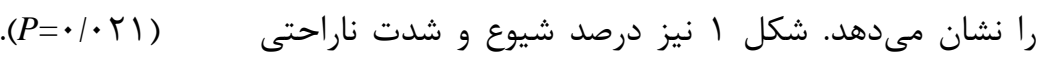

جدول ا. مشخصات دموكرافيك افراد

\begin{tabular}{|c|c|c|c|c|}
\hline حداكثر & حداقل & انحراف معيار & ميانكين & \\
\hline $8 \Lambda$ & rA & s/DAV & $\mu \varphi / \Lambda$. & سن \\
\hline ru & 1 & ه/ᄉৎ૬ & $\mid Q / 99$ & سابقهُ كار \\
\hline TN/GT & 19/rT & r/IrAlq & $r \Delta / \digamma \& A T$ & BMI \\
\hline \multicolumn{4}{|c|}{ IVT } & تعداد نمونه \\
\hline
\end{tabular}

جدول r. جراوانى و دستهبندى نمرة نهايى روش ROSA

\section{درصد فراوانى}

فراوانى

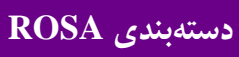

\begin{tabular}{|c|c|c|}
\hline . & . & $r>$ \\
\hline & س & س- \\
\hline gr/द & 11. & $0_{+}$ \\
\hline $1 \ldots$ & $I^{2}$ & كل \\
\hline
\end{tabular}

and

جدول r. ميزان شيوع درد در اعضاى مختلف بدن

\begin{tabular}{|c|c|c|c|}
\hline درصد & اعضاى بدن & درصد & اعضاى بدن \\
\hline 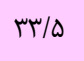 & مج راست & $\Delta r / \Lambda$ & كردن \\
\hline$r r / q$ & مج حֶ & $19 / \mathrm{V}$ & تحتانى يشت \\
\hline$r r / q$ & ران راست & $\forall \wedge$ & فوقانى يشت \\
\hline$r \cdot / q$ & ران حֶٍ & $F V / F$ & شانه راست \\
\hline rq/q & زانوى راست & $N F / D$ & نشيمن كاه \\
\hline$k r / 9$ & زانوى حٍ" & il & شانه جֶ \\
\hline rN/V & ساق راست & $m+/$ & بازوى راست \\
\hline$M F / V$ & ساق خٍ & II/ & بازوى جֶٍ \\
\hline$r \cdot / 1$ & كف پاى راست & $\mathrm{rV} / \mathrm{s}$ & ساعد راست \\
\hline$r \Delta / \mu$ & كف پِى جֶٍ & $m F / l$ & ساعد جֶٍ \\
\hline
\end{tabular}


60

๙0

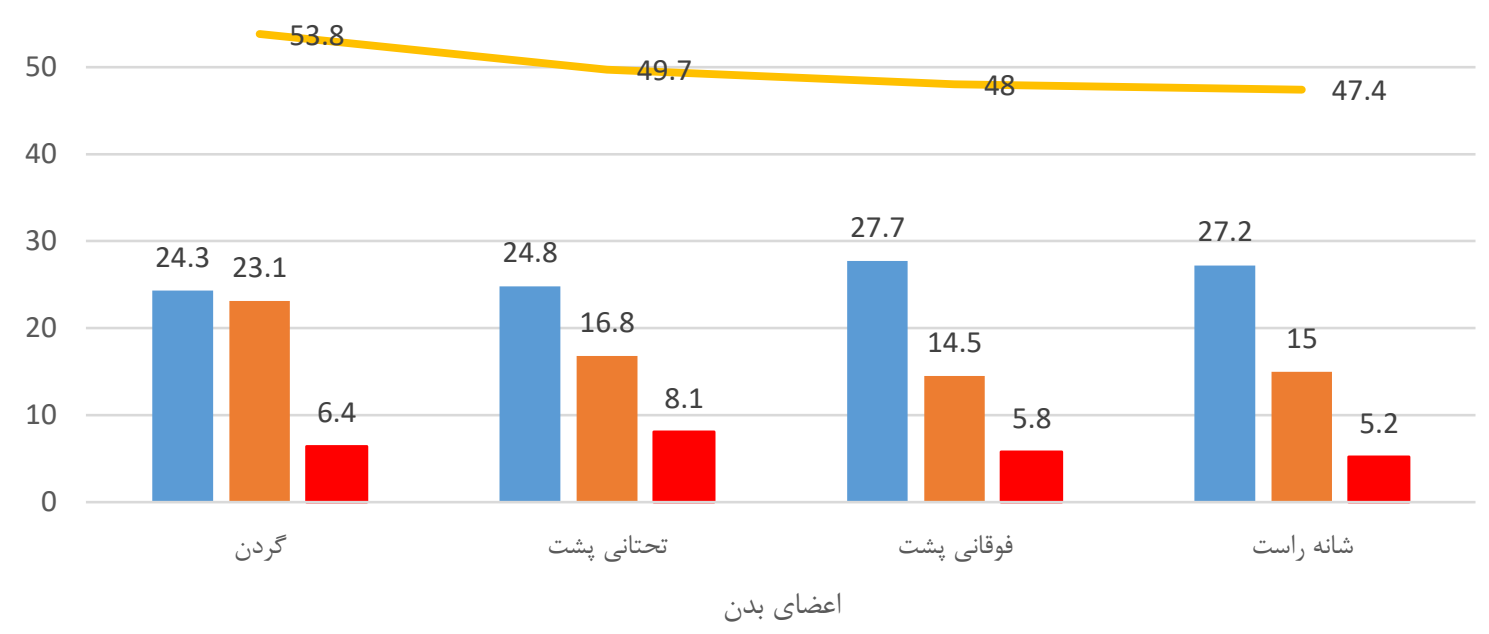

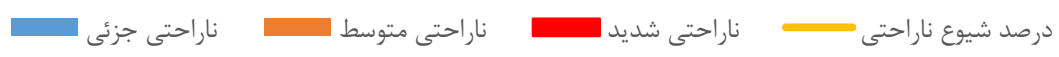

شكل ا. درصد شيوع ناراحتى در اعضاى بدن و شدت آن

نفر از كاركنان ادارى دانشخاه هنر اصفهان يرداختند، ميانگين

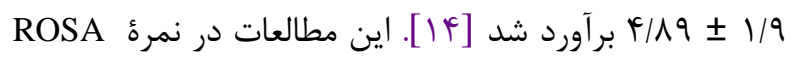
با مطالعئ حاضر همخوانى دارند. مطالعئ Aneela Umar و

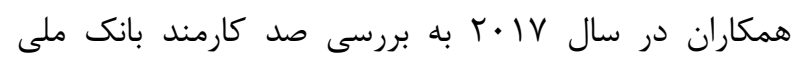

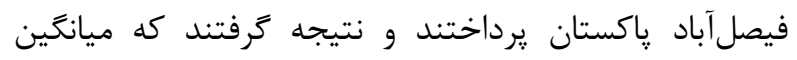
نمرات ROSA برابر 91VA شركت كنندگان نيز نمرهٔ بيش از ه را به دابه دست آوردند كه از مطالعهُ حاضر بيشتر است. دليل اين امر تفاوت در شرايط كار

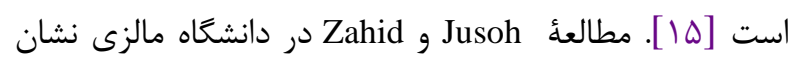
مىدهد نمرات ROSA در بخش هشدار قرار دارند [19].

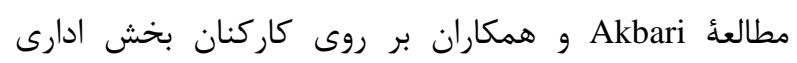

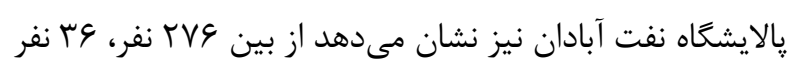

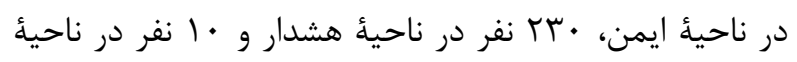

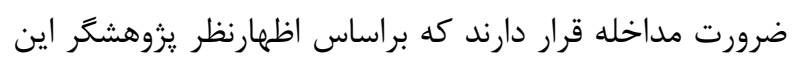
سازمان از نظر اركونومى ادارى در شرايط خوبى قرار دارد [IV] فئ.

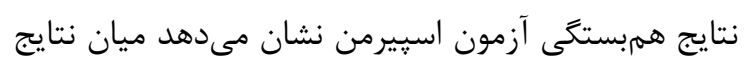
و ROSA Sohrabi روش CMDQ با روش هاى RULA و ROSA يرداختند و نتيجه عرفتند كه ميان نمرهٔ نهايى ناراحتى كل بدن با نتايج RULA

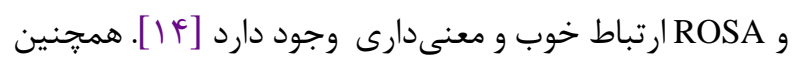
با مطالعه Ferasati و همكاران كه بين نمره

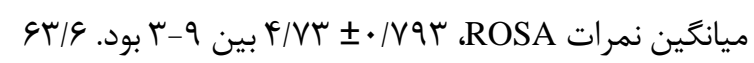
درصد يوسجرها در سطح مداخله قرار زرفتند كه نيازمند ارزيابى ندي

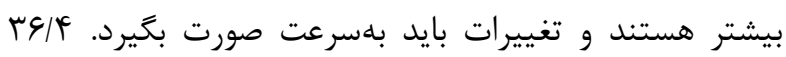
درصد نيز در گروه هشدار قرار زرفتند كه نيازمند توجه و كنترل

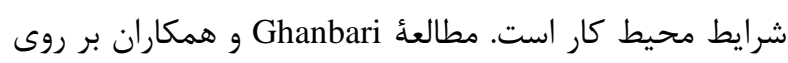
צو نفر از كاربران كامييوتر بخش ادارى دانشعاه اصفهان نشان

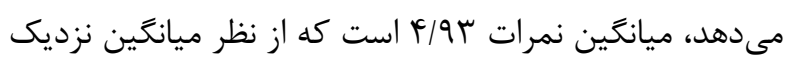

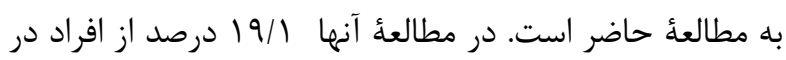

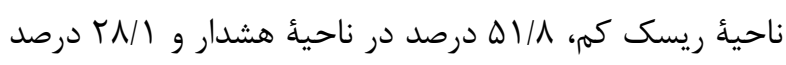

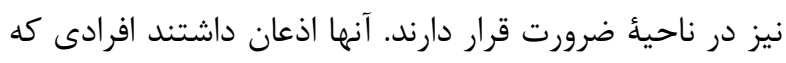

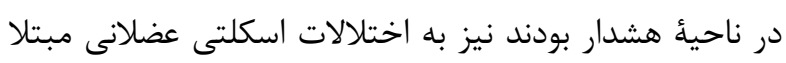

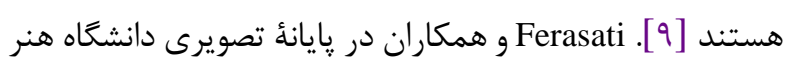
اصفهان به روش ROSA به ميانخين نمره

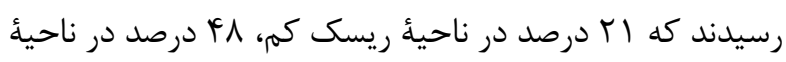
هشدار و اس درصد در ناحئ ضرورت مداخله قرار زرفتند Samaei .[1] ن TVF

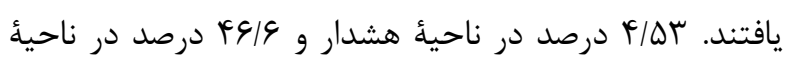

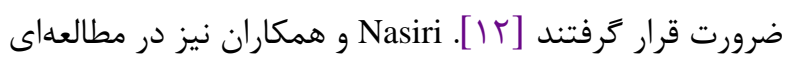
درباره بانك سيه، در دو گروه شاهد و مداخله قبل از از انجام

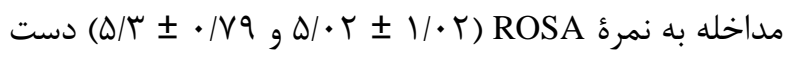

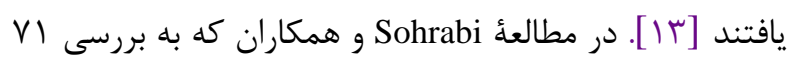


داشت بود انجام مىشد. همجنين علت ناراحتى در قسمت

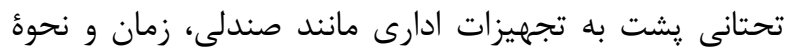

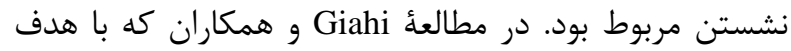

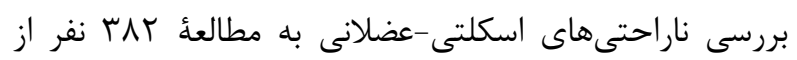

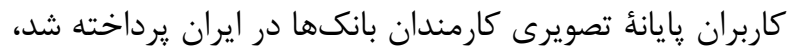

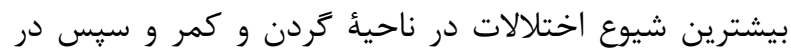

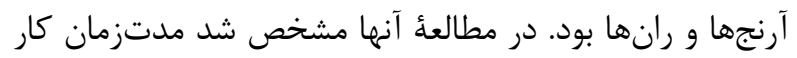
با رايانه و استراحت ناكافى از جمله عوامل مؤثر در ايجاد

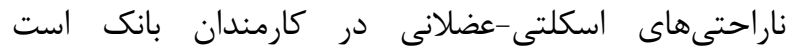

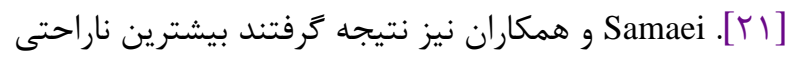

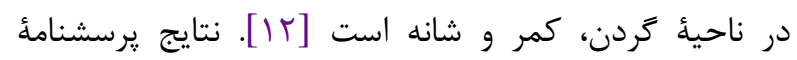
در مطالعُ Aneela Umar و همكاران بر روى كارمندان بانك نشان داد بيشترين شيوع اختلال در ناحئ كردن، كمر و و دان

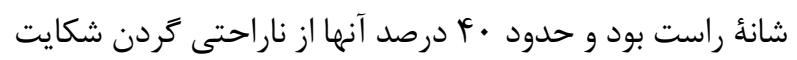

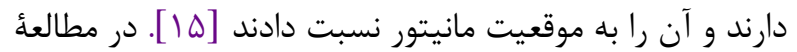

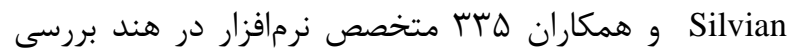

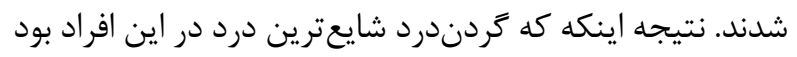

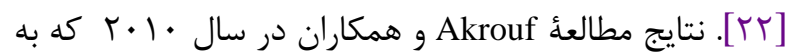
بررسى • VD نفر از كاركنان ادارى بانك در كشور كويت

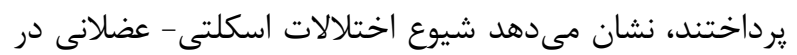

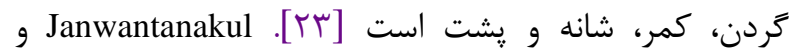

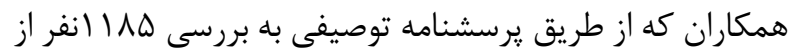

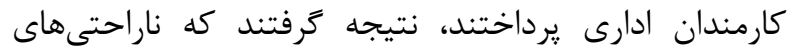

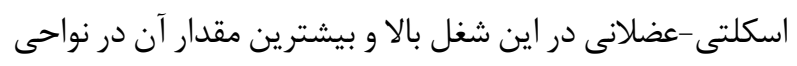

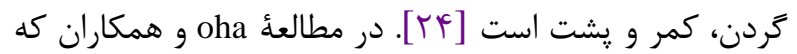

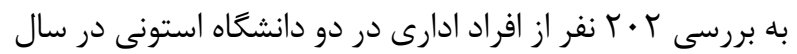

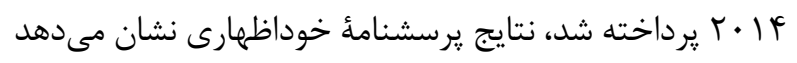

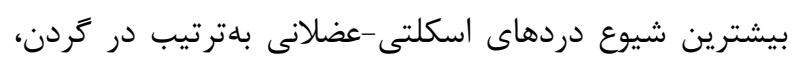

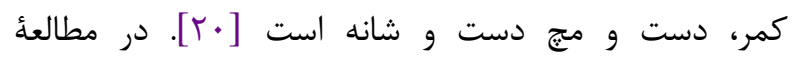
Mirmohammadi

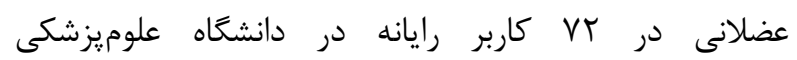

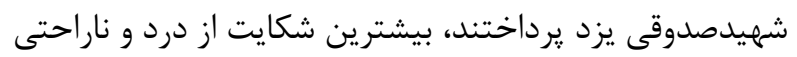

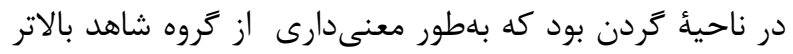

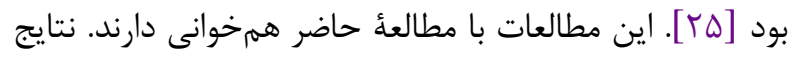

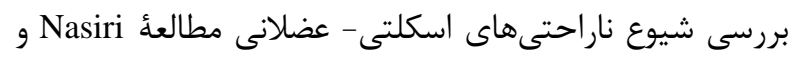
همكاران در كارمندان قبل از اجراى مداخلات نشان مئى ندهددر

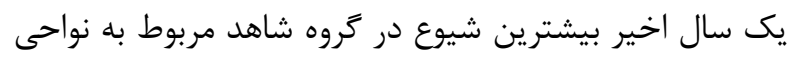
كردن، يشت و كمر و در كروه مداخله مربوط به كَردن، شانهها
ROSA و بخشهاى آن رابطؤ معنى دار مثبت و مستقيمى پيدا

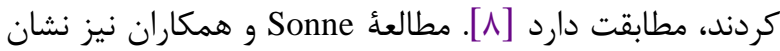
مى دهد بين نمرة ROSA و ناراحتى كاركنان در VT VT ايستكاه

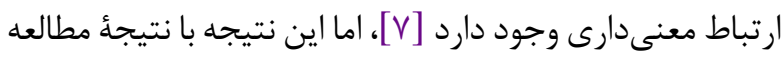
مطالعd Akbari و همكاران همخوانى ندارد. دليل اين امر ممكن

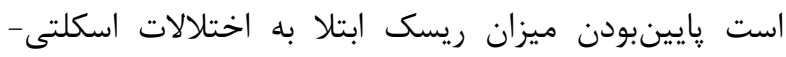

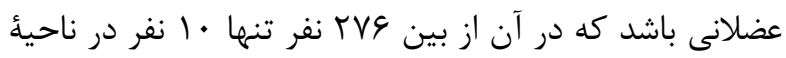
خطر قرار داشتند [IV]. نتيجأ ديخرى از اين مطالعه نشان

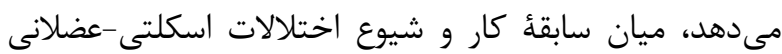

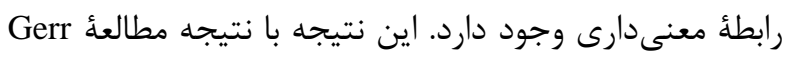

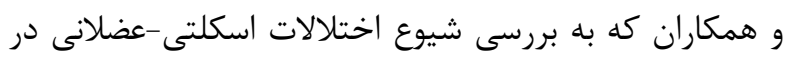

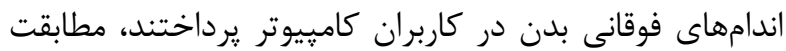

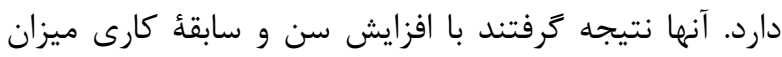

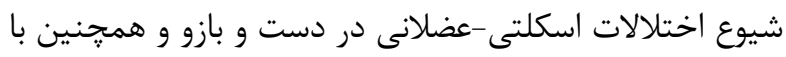
افزايش سن در شانه و كردن افزايش مىيابد [1/]]. همجنين Ghanbari

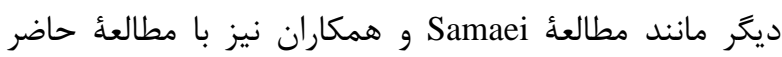
همخوانى دارد. براساس اين مطالعات با افزايش يك سال سال سابقئ

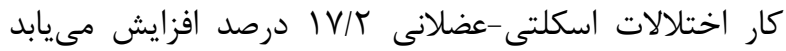

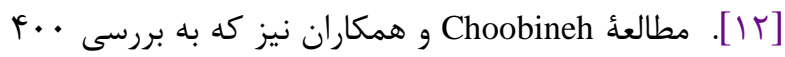

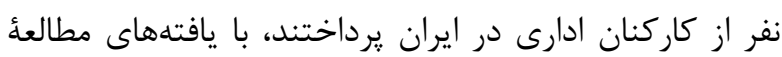

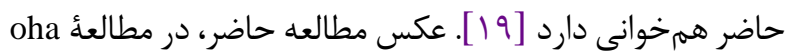

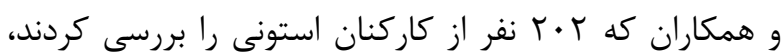

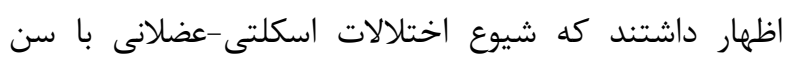
ارتباط ندارد [•r]. آزمون كروسكال واليس نشان داد ميان

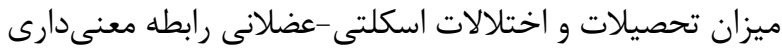

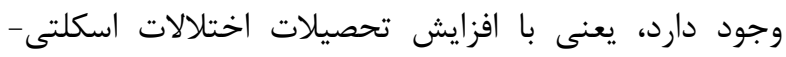

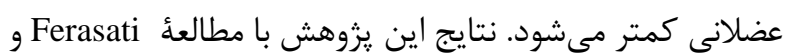
همكاران همسو و با مطالعه Choobineh و همكاران غيرهمسو است كه مىتواند به دليل يراكندگى سطح تحصيلات

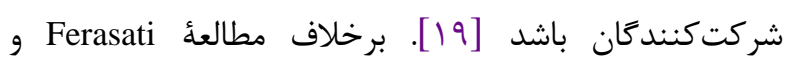
همكاران ميان ميزان تحصيلات و نمرة من ROSA اين ارتباط

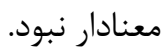

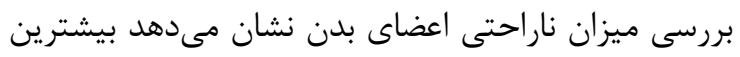

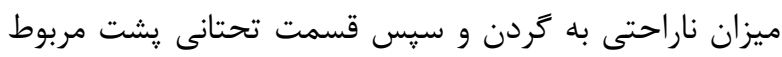

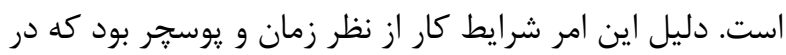

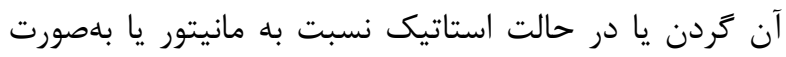

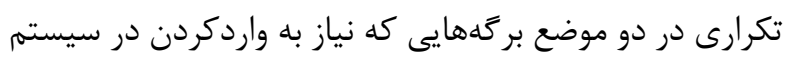


از روى نمرهٔ نهايى صورت بخيرد و در كنار آن بايد نمرءٔ اعضاى

$$
\text { بدن نيز ارزيابى شود. }
$$

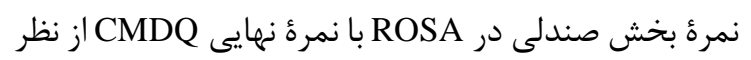

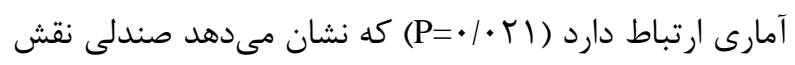

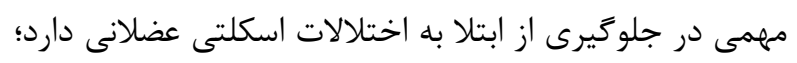

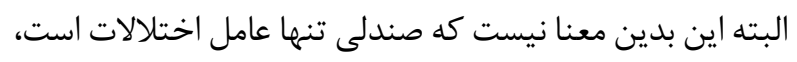

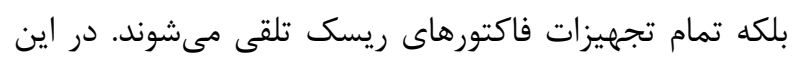

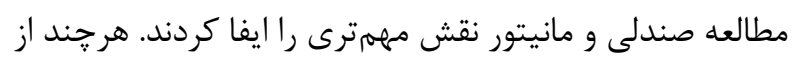

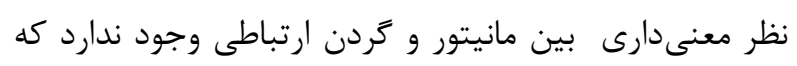

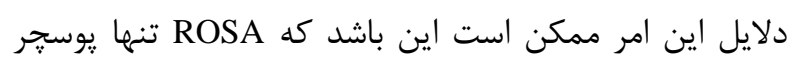

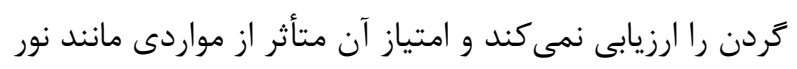

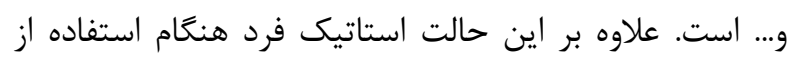

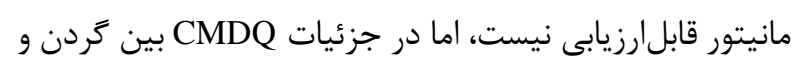

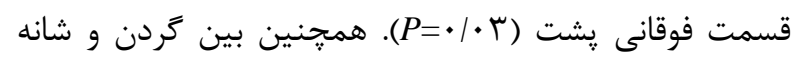

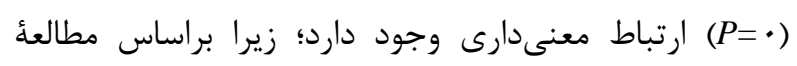

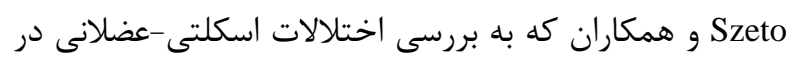

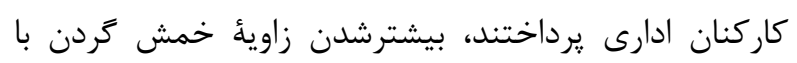

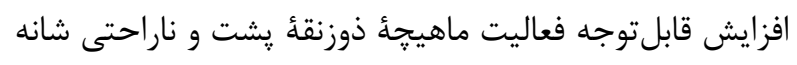

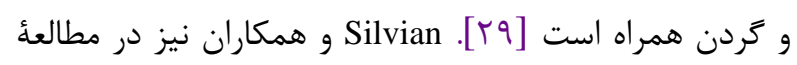

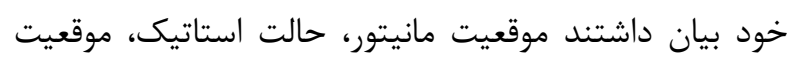

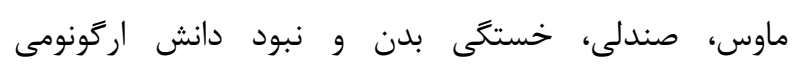

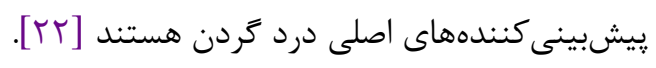

\section{نتيجه كَيرى}

در اين مطالعه بخش زيادى از يوسجر افراد در ناحية ضرورت آناد

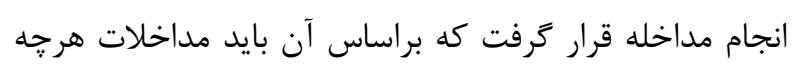

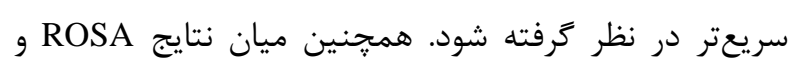

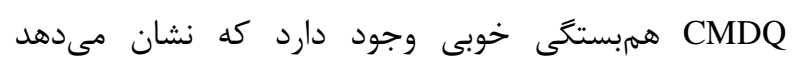
اختلالات اسكلتى-عضلانى افراد مدنظر به شغل وجنى آنها مربوط

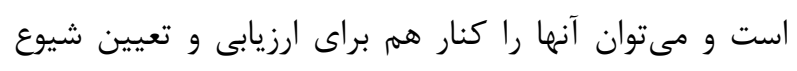

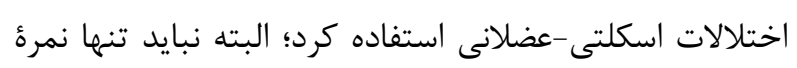

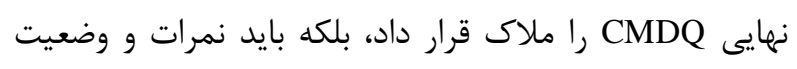

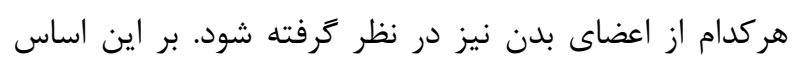

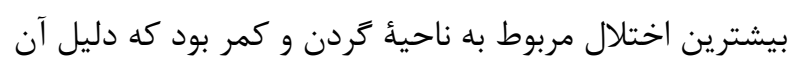

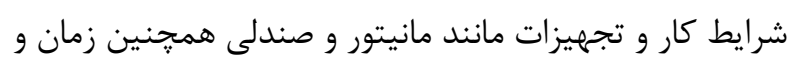

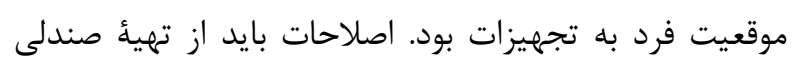

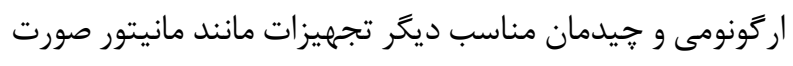

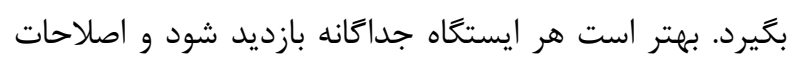

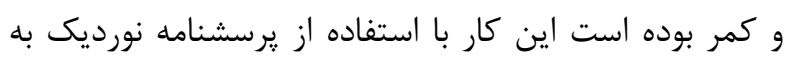

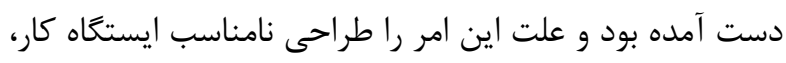

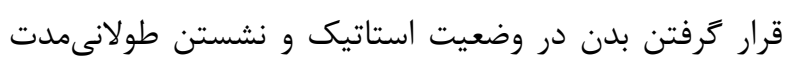

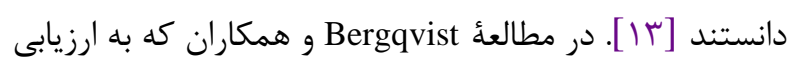

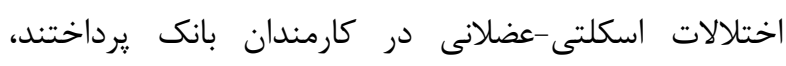

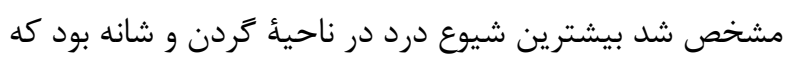

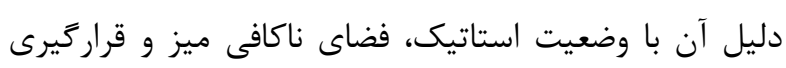

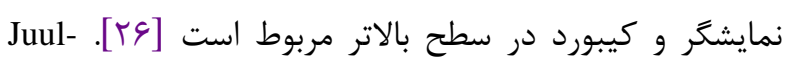
Jensen و Kristensen كارد TDV

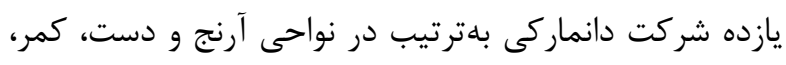

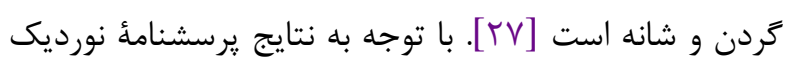
Ghanbari

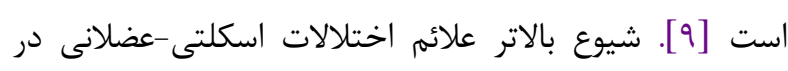

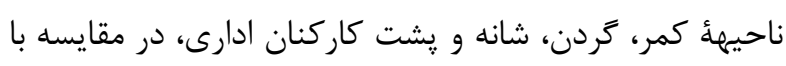

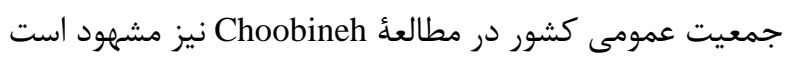

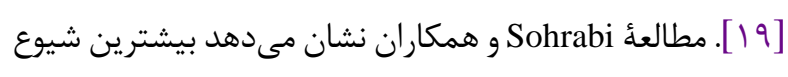

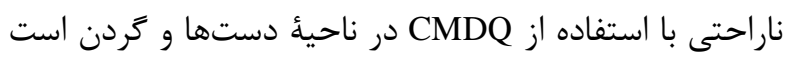

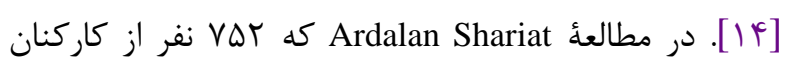

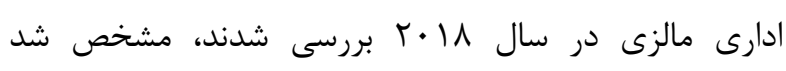

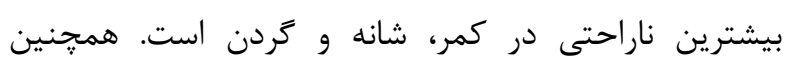

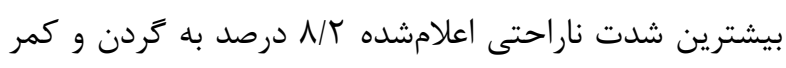

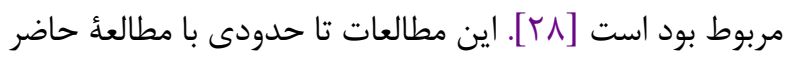

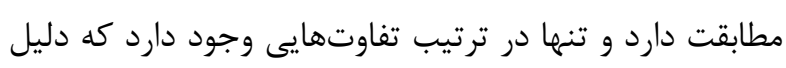

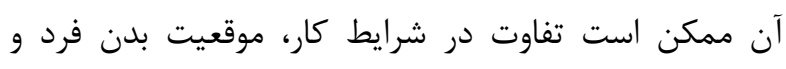

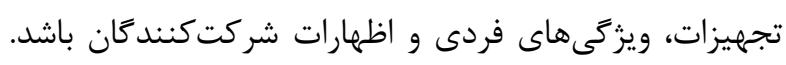

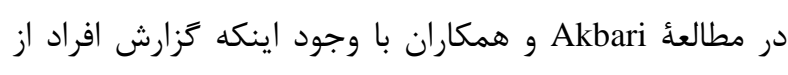

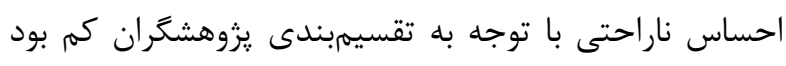

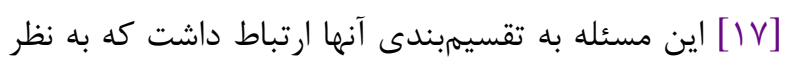

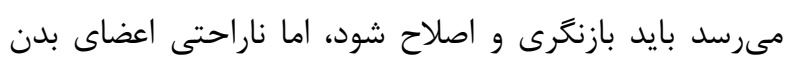

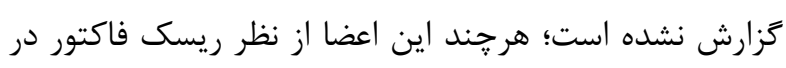

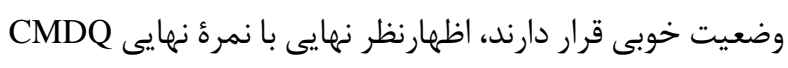

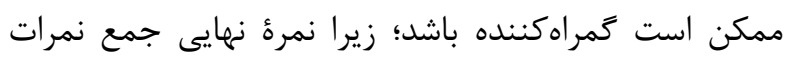

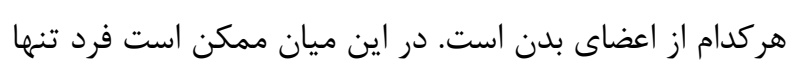

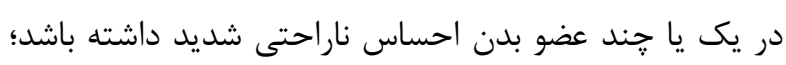

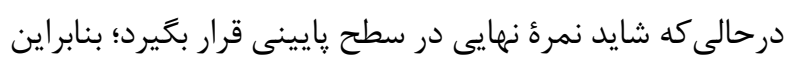

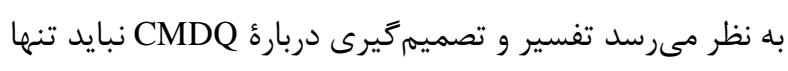




$$
\begin{aligned}
& \text { شده است. بدينوسيله از همكارى معاونت يزوهشى اين دانشخاه، }
\end{aligned}
$$

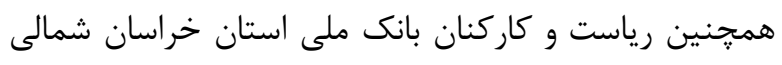

$$
\begin{aligned}
& \text { سياسگزارى مىشود. }
\end{aligned}
$$$$
\text { كد كميتـُ اخلاق }
$$

IR.MAZUMS.REC.1398.5104

$$
\text { تعارض منافع }
$$$$
\text { مازندران تامين شده مالى ماسلى اين مطالعه توسط دانشعاه علوم يزشكى }
$$

\section{References}

1. Gerr F, Marcus M, Monteilh C. Epidemiology of musculoskeletal disorders among computer users: lesson learned from the role of posture and keyboard use. Journal of Electromyography and Kinesiology. 2004 Feb 1;14(1):25-31. [DOI:10.1016/j.jelekin.2003.09.014] [PMID]

2. Robertson MM, Ciriello VM, Garabet AM. Office ergonomics training and a sit-stand workstation: Effects on musculoskeletal and visual symptoms and performance of office workers. Applied ergonomics. 2013 Jan 1;44(1):7385. [DOI:10.1016/j.apergo.2012.05.001] [PMID]

3. Cho CY, Hwang YS, Cherng RJ. Musculoskeletal symptoms and associated risk factors among office workers with high workload computer use. Journal of Manipulative and Physiological therapeutics. 2012 Sep 1;35(7):534-40. [DOI:10.1016/j.jmpt.2012.07.004] [PMID]

4. Bernard BP, Putz-Anderson V. Musculoskeletal disorders and workplace factors; a critical review of epidemiologic evidence for work-related musculoskeletal disorders of the neck, upper extremity, and low back.

5. Sanchez-Lite A, Garcia M, Domingo R, Sebastian MA. Novel ergonomic postural assessment method (NERPA) using product-process computer aided engineering for ergonomic workplace design. PloS one. 2013;8(8). [DOI:10.1371/journal.pone.0072703] [PMID] [PMCID]

6. World Health Organization. Global tuberculosis report 2013. World Health Organization; 2013.

7. Sonne M, Villalta DL, Andrews DM. Development and evaluation of an office ergonomic risk checklist: ROSARapid office strain assessment. Applied ergonomics. 2012 Jan 1;43(1):98-108. [DOI:10.1016/j.apergo.2011.03.008] [PMID]

$$
\begin{aligned}
& \text { براساس ارزيابى و راحتى/ناراحتى فرد صورت بخيرد. بايد در نظر } \\
& \text { داشت علاوه بر مداخلات مهندسى، آموزش و روعايت راحتى اصول }
\end{aligned}
$$

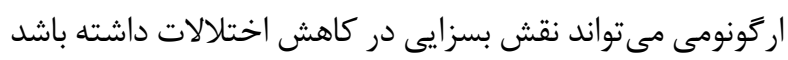

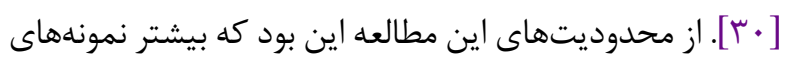

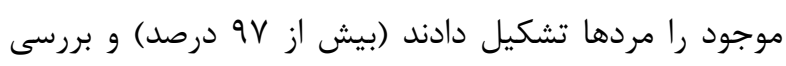

$$
\begin{aligned}
& \text { اختلالات در هر دو جنس امكانيذير نبود. }
\end{aligned}
$$

$$
\text { تقدير و تشكر }
$$$$
\text { مطالعهُ حاضر بر گرفته از ياياننامهاى با عنوان "بررسى شيوع }
$$

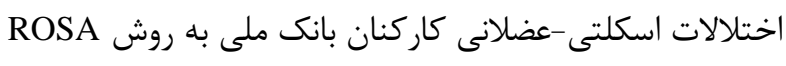$$
\text { و و و ارتباط آن با طراحى و جيدمان تجهيزات ادارى در }
$$

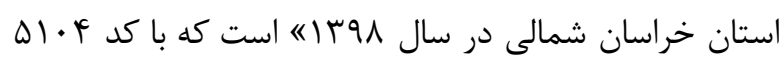$$
\text { در شوراى يروهشى دانشعاه علوميزشكى و خدمات بهداشتى - }
$$$$
\text { درمانى مازندران تصويب و با حمايت مالى اين دانشگًاه انجام }
$$

8. Ferasati F, Jalilian M. Evaluation of WMSDs in VDT users with Rapid office strain assessment (ROSA) method. Iranian Journal of Ergonomics. 2014 Mar 15;1(3):65-74.

9. Ghanbary-Sartang A, Habibi H. Evaluation of musculoskeletal disorders to method Rapid Office Strain Assessment (ROSA) in computers users. jpm. 2015; 2 (1) :47-54

10. Afifehzadeh-Kashani H, Choobineh A, Bakand S, Gohari MR, Abbastabar H, Moshtaghi P. Validity and reliability of farsi version of Cornell Musculoskeletal Discomfort Questionnaire (CMDQ).

11. Erdinc O, Hot K, Ozkaya M. Turkish version of the Cornell Musculoskeletal Discomfort Questionnaire: cross-cultural adaptation and validation. Work. 2011 Jan 1;39(3):251-60. [DOI:10.3233/WOR-2011-1173] [PMID]

12. Samaei SI, Tirgar A, Khanjani N, Mostafaee M, Bagheri Hosseinabadi M, Amrollahi M. Assessment of ergonomics risk factors influencing incidence of musculoskeletal disorders among office workers. Health and Safety at Work. 2015 Dec 10;5(4):1-2.

13. Nasiri I, Motamedzade M, Golmohammadi R, Faradmal J. Assessment of risk factors for musculoskeletal disorders using the Rapid Office Strain Assessment (ROSA) Method and implementing ergonomics intervention programs in Sepah Bank. Health and Safety at Work. 2015 Jul 15;5(2):47-62.

14. Sohrabi M, Faridizad AM, Farasati F. Comparing results of musculoskeletal disorders evaluation in computer users with CMDQ, RULA and ROSA methods. scientific journal of ilam university of medical sciences. 2015 Oct 10;23(4):53-62.

15. Umar A, Kashif M, Zahid N, Sohail R, Arsh A, Raqib A, Zada P. The prevalence of musculoskeletal disorders and work-station evaluation in bank employees. Physikalische 
Medizin, Rehabilitationsmedizin, Kurortmedizin. 2019 Apr;29(02):99-103. [DOI:10.1055/a-0756-9782]

16. Jusoh F, Zahid MN. Ergonomics Risk Assessment among support staff in Universiti Malaysia Pahang. InIOP Conference Series: Materials Science and Engineering 2018 Mar (Vol. 319, No. 1, p. 012059). IOP Publishing. [DOI:10.1088/1757-899X/319/1/012059]

17. Akbari J, Kazemi M, Mazareie A, Moradirad R, Razavi A. The Ergonomic assessment of exposure to risk factors that cause musculoskeletal disorders in Office workers by using ROSA. scientific journal of ilam university of medical sciences. $2017 \quad$ Jul 10;25(2):8-17. [DOI:10.29252/sjimu.25.2.8]

18. Gerr F, Marcus M, Ensor C, Kleinbaum D, Cohen S, Edwards A, Gentry E, Ortiz DJ, Monteilh C. A prospective study of computer users: I. Study design and incidence of musculoskeletal symptoms and disorders. American journal of industrial medicine. 2002 Apr;41(4):221-35. [DOI:10.1002/ajim.10066] [PMID]

19. Choobineh AR, Rahimi Fard HO, Jahangiri M, Mahmood Khani SO. Musculoskeletal injuries and their associated risk factors. Iran Occupational Health. 2012 Jan 15;8(4):7081.

20. Oha K, Animägi L, Pääsuke M, Coggon D, Merisalu E. Individual and work-related risk factors for musculoskeletal pain: a cross-sectional study among Estonian computer users. BMC musculoskeletal disorders. 2014 Dec 1;15(1):181. [DOI:10.1186/1471-2474-15-181] [PMID] [PMCID]

21. Giahi O, Khoubi J, Barkhordari A, Darvishi E, Ebrahemzadih M. Daily visual display terminal use and musculoskeletal disorders among Iranian bank tellers. Journal of Advances in Environmental Health Research. 2014 Jan 1;2(1):1-6.

22. Silvian SP, Maiya A, Resmi AT, Page T. Antecedents of work related musculoskeletal disorders in software professionals. International Journal of Enterprise Network Management. 2011 Jan 1;4(3):247-60. [DOI:10.1504/IJENM.2011.041155]

23. Akrouf QA, Crawford JO, Al Shatti AS, Kamel MI. Musculoskeletal disorders among bank office workers in Kuwait.

24. Janwantanakul P, Pensri P, Jiamjarasrangsri V, Sinsongsook T. Prevalence of self-reported musculoskeletal symptoms among office workers. Occupational medicine. 2008 Sep 1;58(6):436-8. [DOI:10.1093/occmed/kqn072] [PMID]

25. Mirmohammadi SJ, Mehrparvar AH, Soleimani H, Lotfi MH, Akbari HA, Heidari N. Musculoskeletal disorders among video display terminal (VDT) workers comparing with other office workers. Iran Occupational Health. 2010 Jul 15;7(2):11-4.

26. Bergqvist $\mathrm{U}$, Wolgast $\mathrm{E}$, Nilsson $\mathrm{B}$, Voss $\mathrm{M}$. Musculoskeletal disorders among visual display terminal workers: individual, ergonomic, and work organizational factors. Ergonomics. 1995 Apr 1;38(4):763-76. [DOI:10.1080/00140139508925148] [PMID]

27. Juul-Kristensen B, Jensen C. Self-reported workplace related ergonomic conditions as prognostic factors for musculoskeletal symptoms: the "BIT" follow up study on office workers. Occupational and environmental medicine.
2005
Mar
$1 ; 62(3): 188-94$
[DOI:10.1136/oem.2004.013920] [PMID] [PMCID]

28. Shariat A, Cardoso JR, Cleland JA, Danaee M, Ansari NN, Kargarfard M, Tamrin M, Bahri S. Prevalence rate of neck, shoulder and lower back pain in association with age, body mass index and gender among Malaysian office workers. Work. 2018 Jan 1;60(2):191-9. [DOI:10.3233/WOR182738] [PMID]

29. Szeto GP, Straker LM, O'Sullivan PB. A comparison of symptomatic and asymptomatic office workers performing monotonous keyboard work-1: neck and shoulder muscle recruitment patterns. Manual therapy. 2005 Nov 1;10(4):270-80. [DOI:10.1016/j.math.2005.01.004] [PMID]

30. Safarian MH, Rahmati-Najarkolaei F, Mortezapour A. A Comparison of the Effects of Ergonomic, Organization, and Education Interventions on Reducing Musculoskeletal Disorders in Office Workers. Health Scope. 2019 Feb 28;8(1). 